\title{
Helical myofiber orientation after myocardial infarction and left ventricular surgical restoration in sheep
}

\author{
Joseph C. Walker, BS ${ }^{a}$ \\ Julius $\mathrm{M}$. Guccione, $\mathrm{PhD}^{\mathrm{b}, \mathrm{c}}$ \\ Yi Jiang, $M D^{\mathrm{d}, \mathrm{e}}$ \\ Peng Zhang, MD, $\mathrm{PhD}^{\mathrm{c}}$ \\ Arthur W. Wallace, MD, $\mathrm{PhD}^{f}$ \\ Edward W. Hsu, PhD ${ }^{\text {d,e }}$ \\ Mark B. Ratcliffe, $M D^{\mathrm{b}, \mathrm{c}}$
}

See related editorial on page 243.
From the Joint Bioengineering Graduate Group, ${ }^{a}$ University of California Berkeley/ San Francisco, San Francisco, Calif; the Departments of Surgery, ${ }^{b}$ and Anesthesia, ${ }^{f}$ University of California, San Francisco, Calif; the Department of Veterans Affairs Medical Center, ${ }^{\mathrm{c}}$ San Francisco, Calif; the Department of Biomedical Engineering, ${ }^{\mathrm{d}}$ Duke University, Durham, NC; and The Center for in Vivo Microscopy, ${ }^{\mathrm{e}}$ Duke University Medical Center, Durham, NC.

Supported by National Institutes of Health (NIH) grants R01-HL-58759 (Dr Guccione) and R01-HL-63348 (Dr Ratcliffe), a predoctoral fellowship from the American Heart Association ( $\mathrm{Mr}$ Walker), NIH/ NCRR grant P41RR059059 and Whitaker grant RG-01-0438 (Drs Hsu and Jiang), and VA Merit Review (Dr Wallace).

Received for publication Nov 25, 2003; revisions received March 17, 2004; accepted for publication June 1, 2004.

Address for reprints: Julius M. Guccione, $\mathrm{PhD}$, Division of Surgical Services (112D), Department of Veterans Affairs Medical Center, 4150 Clement St, San Francisco, CA 94121 (E-mail: Julius.Guccione@med. va.gov).

J Thorac Cardiovasc Surg 2005;129:382-90 $0022-5223 / \$ 30.00$

Copyright (C) 2005 by The American Association for Thoracic Surgery

doi:10.1016/j.jtcvs.2004.06.006
Objectives: It has been proposed that successful left ventricular surgical restoration should restore normal helical myofiber orientation. A magnetic resonance imaging technique, magnetic resonance diffusion tensor imaging, has been developed to measure myocyte orientation. By using magnetic resonance diffusion tensor imaging, this study tested the hypothesis that (1) myocyte orientation is altered after anteroapical myocardial infarction and (2) left ventricular surgical restoration restores normal helix angles.

Methods: Thirteen sheep underwent anteroapical myocardial infarction (25\% of left ventricular mass). Ten weeks later, animals underwent either aneurysm plication ( $\mathrm{n}$ $=8)$ or sham operations $(n=5)$. Six weeks after this operation, hearts were excised, perfusion fixed in diastole, and underwent magnetic resonance diffusion tensor imaging. Hearts from normal sheep $(n=5)$ were also harvested and imaged. Primary eigenvectors of the diffusion tensors from magnetic resonance diffusion tensor imaging were resolved into helix angles relative to a local wall coordinate system. Transmural samples of the helix angles were compared at the border zone of the aneurysm or repair (or a comparable distance from the base in normal sheep), $1 \mathrm{~cm}$ below the valves, and halfway between.

Results: The helical myofiber orientation did not change after myocardial infarction. However, aneurysm plication caused myofibers in the anterior border zone to rotate counterclockwise $\left(-35.6 \pm 10.5^{\circ}, P=.028\right)$ and those in the lateral border zone to rotate clockwise $\left(34.4 \pm 8.1^{\circ}, P=.031\right)$.

Conclusions: Surgical restoration alters myocyte orientation adjacent to the surgical repair. However, myofiber orientation is not abnormal after myocardial infarction, and thus surgical restoration techniques intent on restoring normal helix angles might not be warranted.

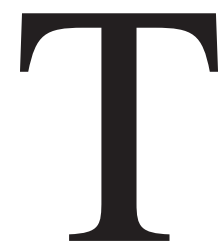

he heart is a complex biologic pump in part because of the orientation of myocytes in the ventricular wall. The orientation of myofibers was first quantified by Streeter and coworkers, ${ }^{1}$ who, by viewing tangential histologic slices through the ventricular wall, showed a smooth transition in the orientation of myocytes from a left-handed helix at the epicardium to a right-handed helix at the endocardium. Other studies have confirmed their results in different species. ${ }^{2,3}$ This helical fiber orientation (helix angle; Figure 1) augments the pumping capabilities of the left ventricle (LV). Mathematic simulations have shown that a myofiber orientation, 


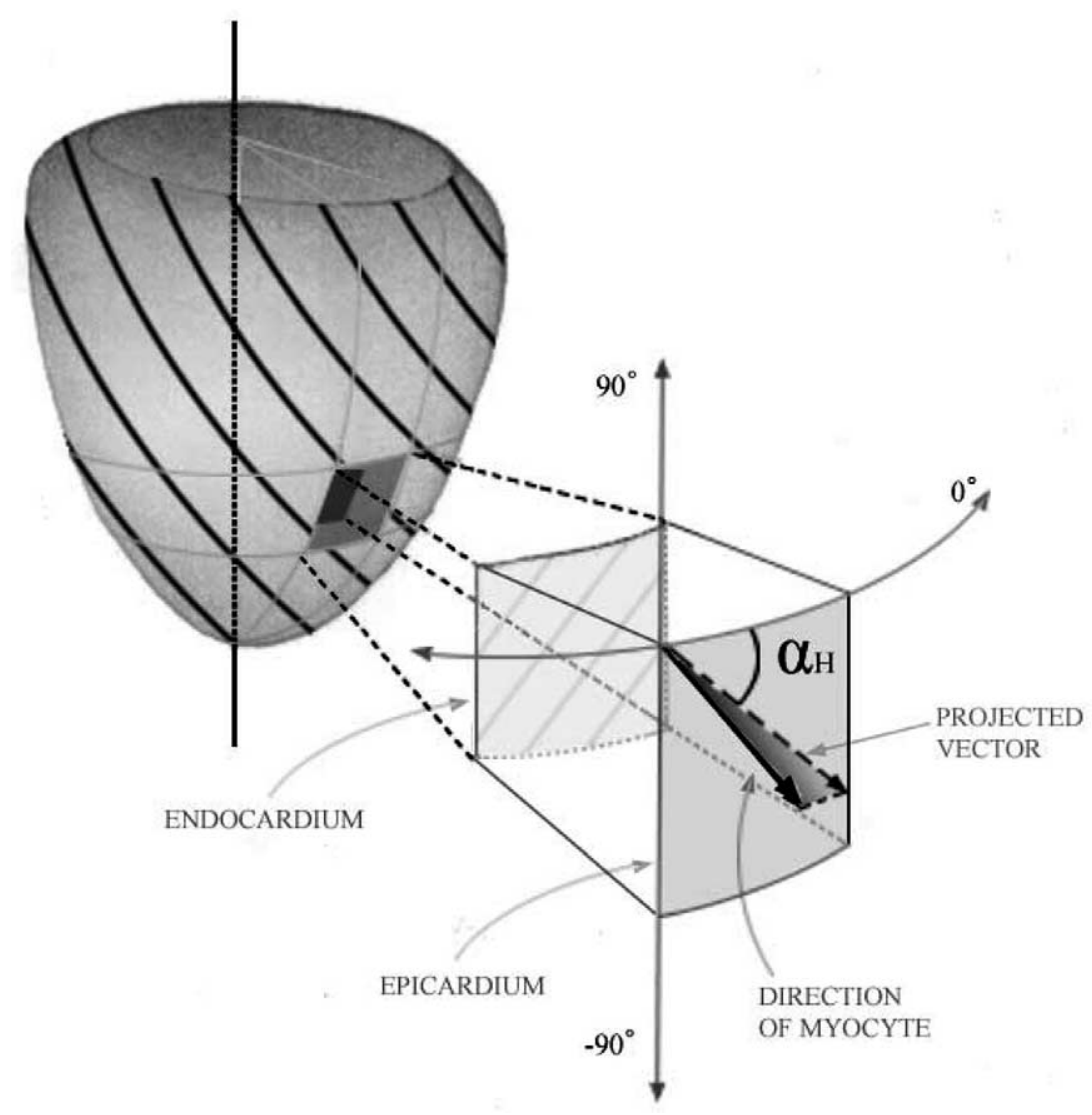

Figure 1. Illustration of the helix angle $\left(\alpha_{H}\right)$. The primary eigenvector of the diffusion tensor obtained from MR-DTI was projected onto the local epicardial tangent plane. The helix angle was calculated relative to this projection and the local circumferential direction.

such as that reported by Streeter and coworkers, ${ }^{1}$ minimizes stress gradients, ${ }^{4}$ results in uniform strain, ${ }^{5}$ and optimizes the ejection fraction. ${ }^{6}$

As an alternative to laborious histologic sectioning to determine myofiber orientation, recent advances in magnetic resonance imaging now allow rapid and nondestructive assessment of muscle fiber orientation throughout the entire heart. Magnetic resonance diffusion tensor imaging (MR-DTI) exploits the anisotropic diffusion of water through ordered tissues. This method has accurately correlated the fastest direction of water diffusion with the histologically measured myofiber helix angles in normally perfused, formalin-fixed, and infarcted myocardium. ${ }^{7-10}$ Already this technique has been used to thoroughly map the fiber orientation in the normal LVs of a rabbit and goat ${ }^{11,12}$ and in rats with myocardial infarctions (MIs). ${ }^{10}$ Before the advent of MR-DTI, the most thorough fiber angle study gathered 12,000 angle measurements in both ventricles of one normal rabbit. ${ }^{2}$ With MR-DTI, the current study yielded more than 200,000 helix angle measurements in the LV in each of 18 hearts. Consequently, subtle differences have been elucidated in this study that could not be detected with previous histologic studies.

Recently, it has been proposed that myofiber helix angles in the LV rotate from oblique directions (ie, not circumferential or longitudinal) to more circumferential directions as the LV dilates during the progression of heart failure. It is also proposed that a beneficial surgical restoration of the dilated LV will restore myofibers in the diseased ventricle to a normal, oblique orientation. ${ }^{13-16}$ However, data supporting these claims are lacking. Previous histologic studies have shown no significant difference in the helix angles between normal and hypertrophied hearts, ${ }^{17,18}$ and Chen and colleagues ${ }^{10}$ reported no significant change in helix angles after infarction in the rat.

The present study used a sheep model of LV aneurysm. This animal model has been previously reported to have a highly reproducible anteroapical infarct of $22.9 \% \pm 2.5 \%$ of the total LV mass, ${ }^{19}$ with adverse remodeling of the LV to approximately 3 times normal end-systolic volume by 10 weeks after infarction. ${ }^{20}$ Infarct plication in this model decreases LV volume and compliance and increases elas- 
tance, but stroke volume, cardiac output, and the slope of the Starling relationship are unchanged. ${ }^{20}$ Using this model, we tested the hypotheses that (1) myocyte orientation is altered after anteroapical MI and (2) surgical LV restoration restores normal (preinfarction) myofiber orientation.

\section{Methods}

Animals used in this study were treated in compliance with the "Guide for the Care and Use of Laboratory Animals" prepared by the Institute of Laboratory Animal Resources, National Research Council, and published by the National Academy Press, revised 1996.

\section{Myocardial Infarction}

Thirteen adult sheep underwent anteroapical MI. Castrated male Dorsett Sheep (40-50 kg) were anesthetized (ketamine, $33 \mathrm{mg} / \mathrm{kg}$ administered intramuscularly, and isoflurane maintenance [2\%-4\% inspired]) and mechanically ventilated (tidal volume, $20 \mathrm{~mL} / \mathrm{kg}$; model 309-0612-800, Ohio Medical Products, Madison, Wis). During a left thoracotomy, ligatures were placed around the left anterior descending and second left anterior descending diagonal coronary arteries at a point $40 \%$ of the distance from the apex to the base and sequentially tightened, causing an anteroapical MI, as previously described. ${ }^{19}$ When present, branches of the posterior descending artery which also perfused this region were ligated $20 \%$ of the distance from the apex to the base. The thoracotomy was closed, and the sheep recovered from anesthesia.

\section{Aneurysm Plication}

In 13 sheep a partial lower sternotomy was performed after achievement of general anesthesia. Pericardial adhesions were divided. In 8 animals (13.4 \pm 2.3 weeks after MI) aneurysm plication was performed without cardiopulmonary bypass. The transition between infarcted aneurysm and uninfarcted myocardium was palpated, and the LV aneurysm was plicated between 2 strips of Dacron felt. Polypropylene sutures (2-0 Prolene, $\mathrm{MH}$ needle; Ethicon Inc, Sommerville, NJ) were passed through the felt, through and through the aneurysm at its border, and through the opposite strip of felt in a horizontal mattress fashion. The sternotomy was closed, and the sheep recovered from anesthesia. Aneurysm plication was performed in each case by the same experienced cardiac surgeon. The remaining 5 animals (15.2 \pm 1.0 weeks after MI) served as sham-operated control animals. The procedure was similar, except the aneurysm was not plicated.

Approximately 10 weeks after the operation, anesthesia was induced, and a median sternotomy was performed. The heart was excised and retrograde perfused through the aorta first with 500 $\mathrm{mL}$ of cold $\left(0^{\circ} \mathrm{C}-5^{\circ} \mathrm{C}\right)$ cardioplegia $(11 \mathrm{mmol} / \mathrm{L} \mathrm{NaCl}, 10 \mathrm{mmol} / \mathrm{L}$ $\mathrm{NaHCO}_{3}, 16 \mathrm{mmol} / \mathrm{L} \mathrm{KCl}, 16 \mathrm{mmol} / \mathrm{L} \mathrm{MgSO}_{4} \cdot 7 \mathrm{H}_{2} \mathrm{O}$, and 1.2 $\left.\mathrm{mmol} / \mathrm{L} \mathrm{CaCl} \mathrm{Cl}_{2}\right)$ and second with $500 \mathrm{~mL}$ of cold $\left(0^{\circ} \mathrm{C}-5^{\circ} \mathrm{C}\right)$ butanedione monoxime solution (BDM solution; $127 \mathrm{mmol} / \mathrm{L} \mathrm{NaCl}$, $1.3 \mathrm{mmol} / \mathrm{L} \mathrm{KH}_{2} \mathrm{PO}_{4}, 0.6 \mathrm{mmol} / \mathrm{L} \mathrm{MgSO}_{4} \cdot 7 \mathrm{H}_{2} \mathrm{O}, 25 \mathrm{mmol} / \mathrm{L}$ $\mathrm{NaHCO}_{3}, 2.3 \mathrm{mmol} / \mathrm{L} \mathrm{KCl}, 11.2 \mathrm{mmol} / \mathrm{L}$ dextrose, $30 \mathrm{mmol} / \mathrm{L} 2,3$ butanedione monoxime, and $2.5 \mathrm{mmol} / \mathrm{L} \mathrm{CaCl}_{2}$ ). Last, the heart was perfusion fixed with $500 \mathrm{~mL}$ of formalin and stored in formalin until it was imaged. An additional 5 hearts were harvested from normal adult sheep and prepared the same way.

\section{Imaging}

Imaging experiments were conducted on a 2.0 T MR instrument (Oxford Instruments, Oxford, United Kingdom) equipped with shielded gradients $(18 \mathrm{G} / \mathrm{cm}$ ) and a Signa console (Epic 5X; General Electric Medical Systems, Milwaukee, Wis). The intact heart was placed inside a 10 -cm-diameter solenoidal radiofrequency coil, with the long axis of the heart parallel to the coil axis. A diffusion-weighted spin-echo pulse sequence was used to acquire 3-dimensional volume images $(10 \times 10 \times 10 \mathrm{~cm}$ field of view, 500-ms time to repetition, 27.288-ms time to echo, and 1 signal average), with diffusion encoding by using a pair of halfsine gradient pulses (10-ms width separated by $15 \mathrm{~ms}$, nominal gradient magnitude of $18 \mathrm{G} / \mathrm{cm})$. The DTI dataset consisted of a b0 $(\mathrm{b} \approx 0)$ and diffusion-weighted images encoded in each of an optimized set of 12 directions. ${ }^{21}$ A reduced-encoding imaging ${ }^{22}$ methodology was used to accelerate the DTI acquisition, where the b0 and diffusion-weighted images were scanned with $256 \times 128$ $\times 128$ (readout $\times$ phase $\times$ slice directions) and $256 \times 64 \times 64$ matrix sizes, respectively. The total acquisition time for the complete DTI dataset was approximately 9.1 hours. In postprocessing the diffusion-weighted images were reconstructed to $256 \times 128 \times$ 128 matrix size through a constrained keyhole method, as described previously. ${ }^{22}$ Diffusion tensors were calculated and diagonalized offline on a pixel-by-pixel basis by using nonlinear leastsquares curve fitting, as in Hsu and colleagues, ${ }^{7}$ according to the signal intensity attenuation equation:

$$
A(T E)=\exp \left[-\left(\mathbf{u}^{\mathbf{T}} \mathbf{D u}\right) \gamma^{2} \int_{0}^{T E}\left(\int_{0}^{t} G(\tau) d \tau\right)^{2} d t\right]
$$

where $t=T E$ is the time to echo, $G$ is the time-varying magnetic field gradient, $\gamma$ is the spin gyromagnetic constant, $u$ is the unit vector in the diffusion-encoding direction, and $D$ is the diagonalized diffusion tensor matrix. The eigenvector corresponding to the largest ranked diffusion tensor eigenvalue was taken to be the fiber orientation.

\section{Angle Calculations}

After imaging, the epicardium and endocardium of the LV were manually contoured in both long-axis and short-axis slices from the level of the valves to the apex, visually excluding the papillary muscles. Similar to the method used by Geerts and associates, ${ }^{11}$ the long axis of the LV was determined by using least-squares regression. This axis was fit through the centroids of epicardial contours in short-axis slices between the valves and either the aneurysm or the site of repair. A cylindrical-polar grid spaced 1 mm longitudinally and $2.5^{\circ}$ circumferentially relative to this axis was then fit in its radial coordinate to the contours by using a Delaunay triangulation of contour points, thus forming the epicardial and endocardial surfaces (Figure 2).

After forming the chamber surfaces, a local wall coordinate system was established for each eigenvector as the nearest epicardial mesh point. Following the method of Scollan and coworkers ${ }^{8}$ (see Figure 2 in Scollan and coworkers' article), the eigenvector was projected onto the local epicardial plane, and the helix angle was calculated between the projection and a circumferential line of latitude (Figure 1). 


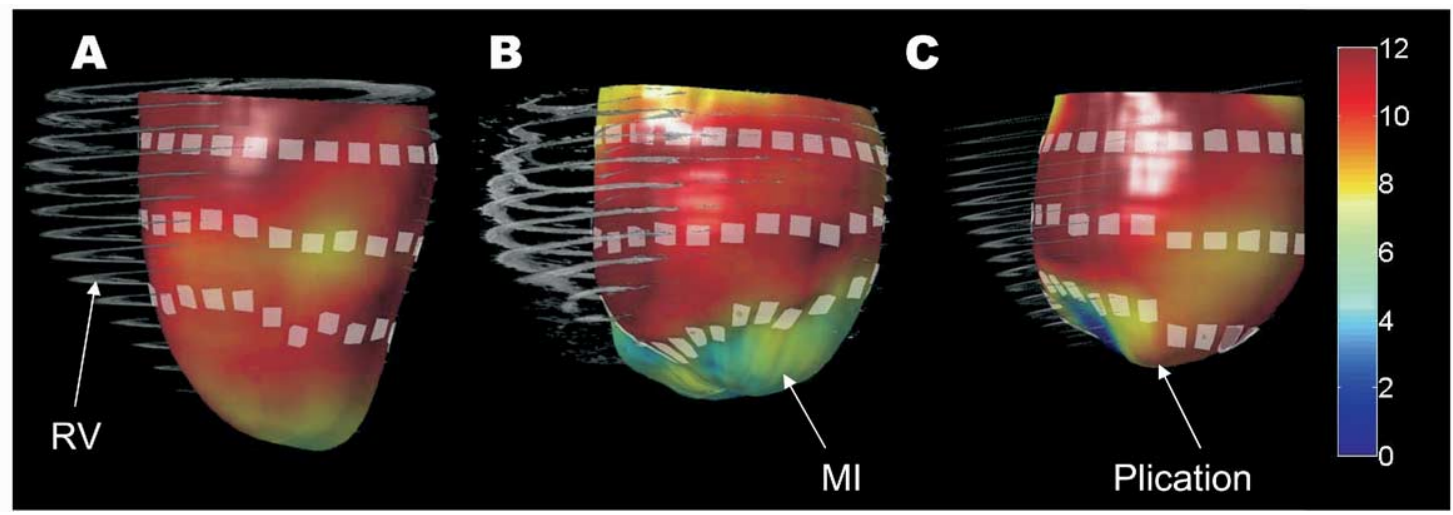

Figure 2. False-color wall-thickness plots rendered on the epicardium in normal (A), infarcted (B), and surgically repaired (C) LVs. The infarcted heart contains a thin apical aneurysm (B) that is surgically eliminated in panel $C$. Gray slices are serial MRI slices and indicate the location of the right ventricle. White patches show where transmural helix angle samples were taken from these hearts. Note that in panel B the ventricle appears foreshortened because the aneurysm is collapsed and a portion of the aneurysm has been removed for mechanical testing. Color-scale units are in millimeters.

\section{Comparisons and Statistics}

Virtual myocardial samples $5 \mathrm{~mm}$ tall and $10^{\circ}$ wide at the epicardium were taken every $15^{\circ}$ around the circumference of the LV beginning at the anterior right ventricular insertion and going counterclockwise as viewed from the base. This was done in 3 different regions: border zone (BZ), equatorial, and basal. The first region followed the $\mathrm{BZ}$ around the $\mathrm{LV}$, with the $\mathrm{BZ}$ defined on the aneurysmal hearts where the myocardium thinned rapidly from normal (ie, $>10 \mathrm{~mm}$ thick to $<7 \mathrm{~mm}$ thick; Figure $2, B$ ). The BZ in the plicated hearts was defined as abutting the surgical repair in the LV free wall or the remaining aneurysm in the septal wall (Figure 2,C). In normal hearts the BZ was defined by the mean distance from the base of BZ samples from the same circumferential location in aneurysmal hearts (Figure 2, A). The basal region was defined as a region of normal wall thickness approximately 1 $\mathrm{cm}$ below the base. The base was determined as the level of the valves by means of visual inspection from 3 orthogonal magnetic resonance imaging (MRI) views. Equatorial samples were defined as half-way between the BZ and base samples. In total, there were 24 samples taken from each of 3 longitudinal locations for a total of 72 samples from each LV.

The helix angles in each sample were broken into deciles through the wall (Figure 3). Visual inspection of the data suggested that changes in helix angles were uniform through the LV wall (Figure 3, A; parallel shift). To test the statistical significance of this parallel shift in helix angles at each location, deciles were averaged across the wall in each animal, and groups were compared by using the Student $t$ test (Figure 4). Thus there were 72 regions (24 at each longitudinal location), each of which received a $t$ test. With 72 regions compared, multiple-comparison corrections would have made any statistical test a prohibitively high barrier. In addition, these large animal models are time consuming and extremely expensive. Therefore to keep the statistical test as sensitive as possible, no multiple-comparison corrections were applied. Meanwhile, statistical significance was interpreted cautiously.
Unless otherwise noted, all data are presented as means $\pm \mathrm{SD}$.

\section{Results}

As shown in Figure 2, the surface reconstruction used for the local angle calculations reproduced well the images obtained from MRI. From the false-color wall-thickness plots, an abrupt transition from normal myocardium to aneurysm is apparent in the thin apical region (Figure 2, B). Also shown are the basal, equatorial, and BZ regions sampled (top to bottom, respectively). Note that the post-MI image (Figure 2, $B$ ) appears foreshortened because aneurysm tissue was removed for mechanical testing before MR-DTI, and the thin aneurysm is not inflated. Note that the remaining blue (ie, thin) area in the postplication heart (Figure 2,C) is in the septum, which was not included in this type of repair.

The smooth transition of helix angles from epicardium to endocardium quantified by Streeter and coworkers ${ }^{1}$ can be seen in the false-color helix angle maps in Figure 5. The geometry at the apex is noticeably different after infarction (Figure 5,B) and surgical intervention (Figure 5, C). Nevertheless, the organization of myofibers in the myocardium shows the same general trend, with a transition from a negative helix angle at the epicardium to a positive helix angle at the endocardium in all 3 groups.

With closer inspection of regions near the site of the operation, a significant change in fiber angles was seen. Specifically, at the anterior BZ, the helix angle rotated counterclockwise after the operation $\left(-31.6 \pm 7.1^{\circ}, P=\right.$ .028; Figure 3, A-I). An equally significant but opposite rotation (ie, clockwise) was seen at the lateral BZ (34.4 \pm $8.1^{\circ}, P=.031$; Figure $\left.3, A-I I\right)$. In regions distal from the 
A

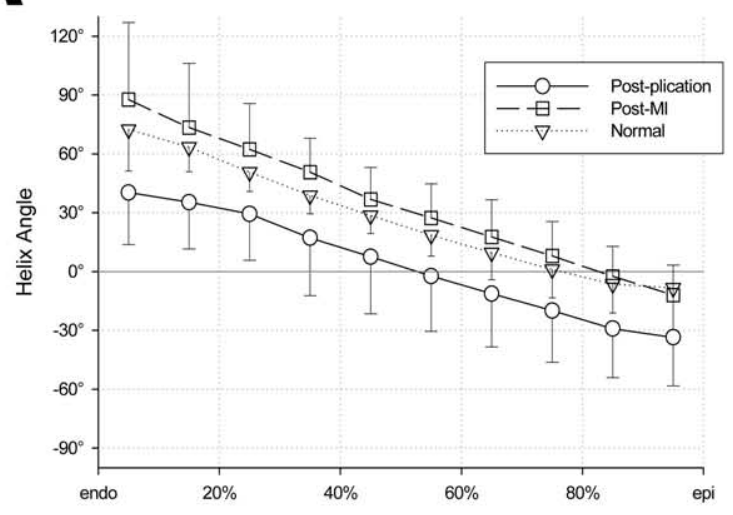

B

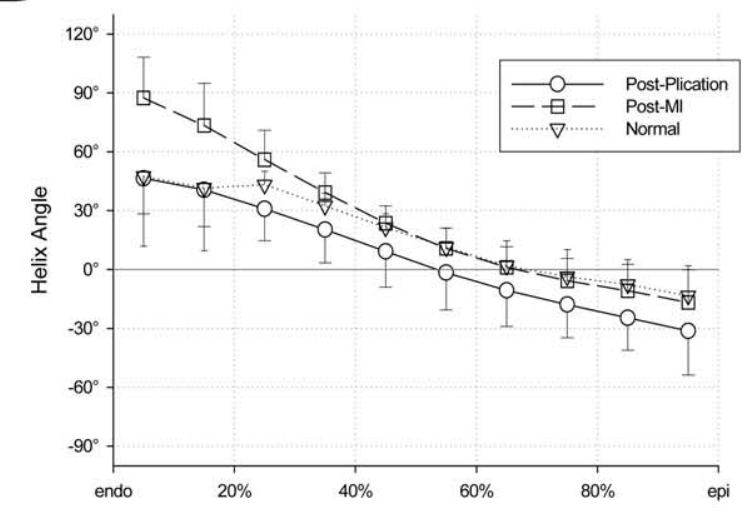

Anterior Basal

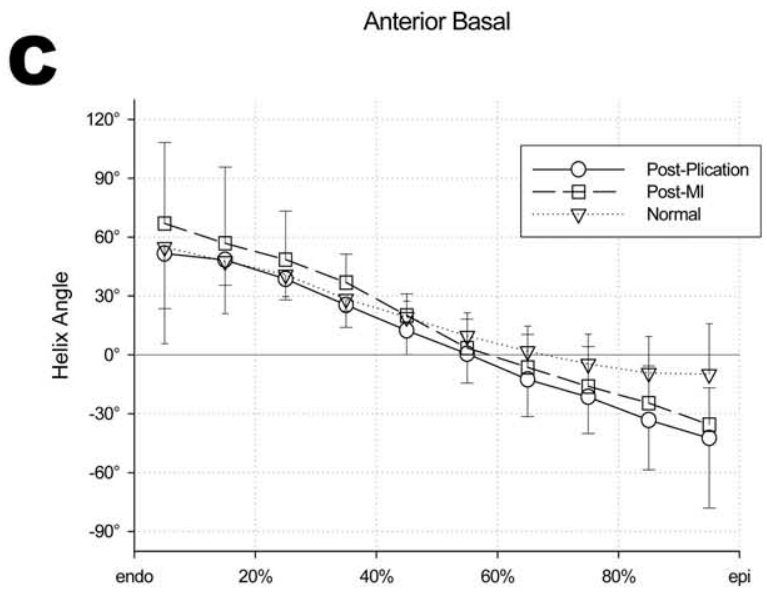

Lateral Border-Zone

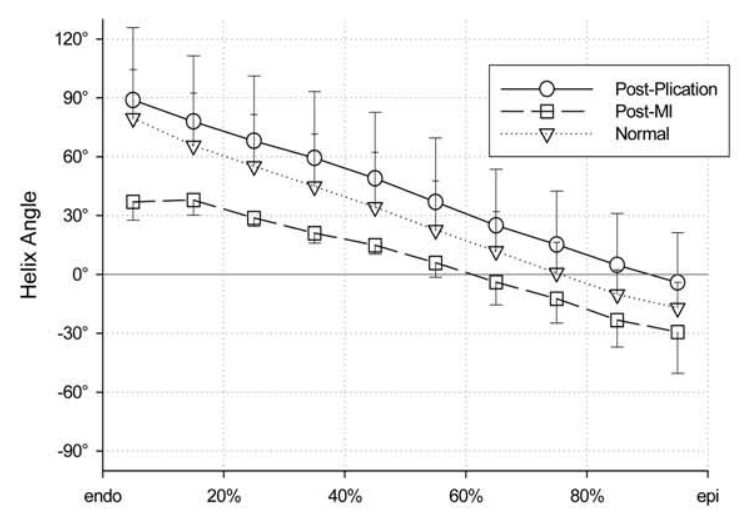

Lateral Equatorial

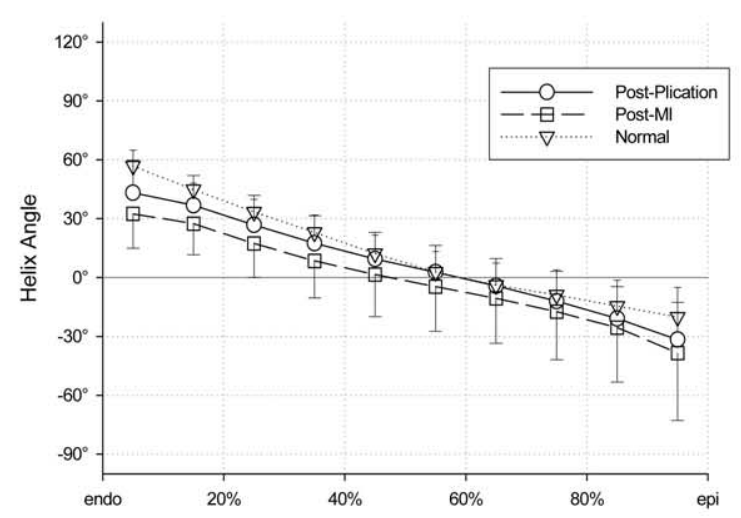

Lateral Basal

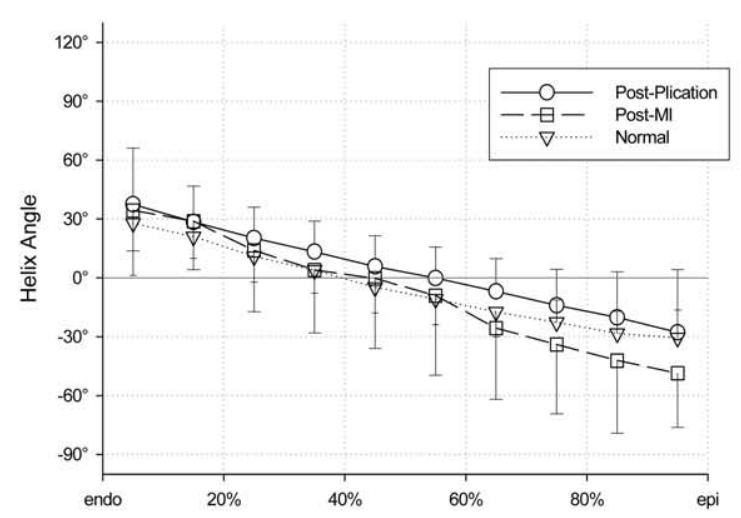

Figure 3. Transmural plots of helix angles from samples at the anterior and lateral wall BZ (A), equator (B), and base (C). Notice the rotation of the helix angles between the surgically repaired and infarcted groups at the BZ. This trend is less distinct at the equatorial region and almost disappears at the basal region. 


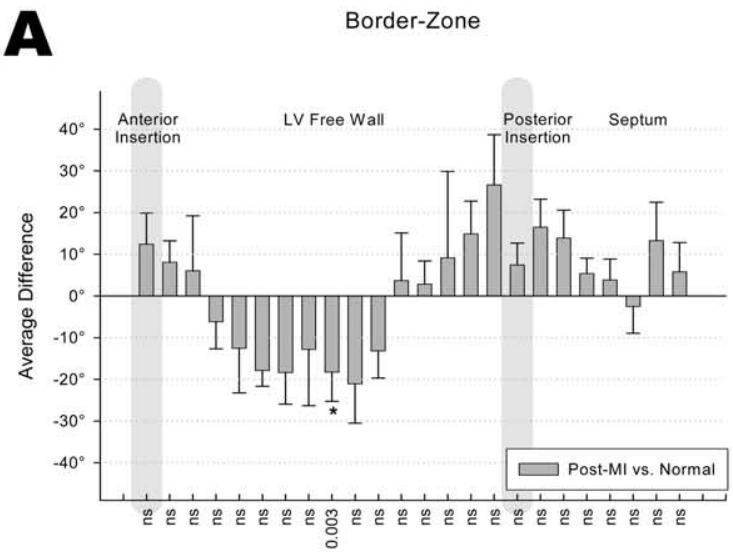

B

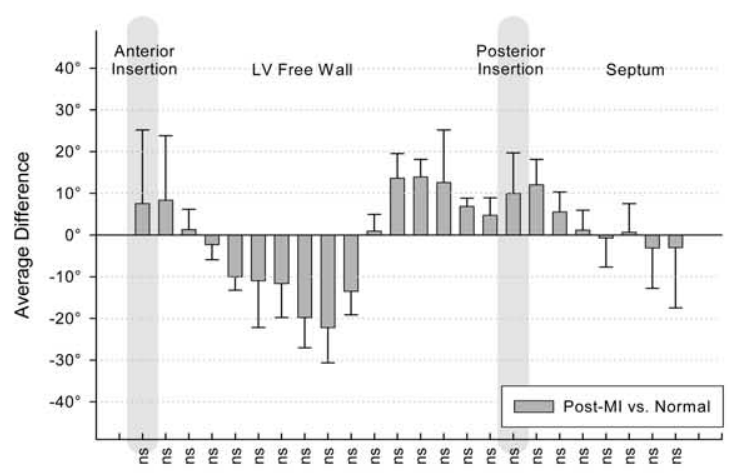

C

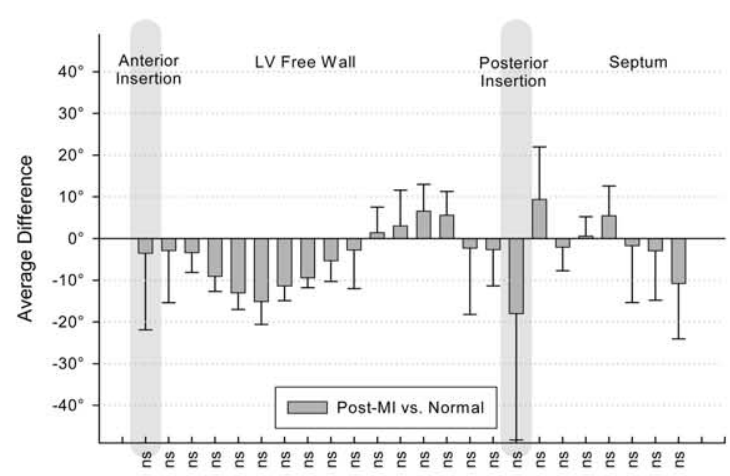

II

Border-Zone

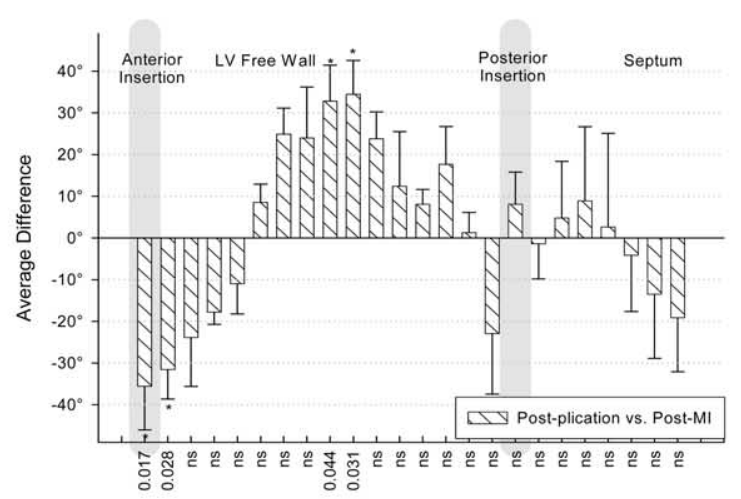

Equatorial

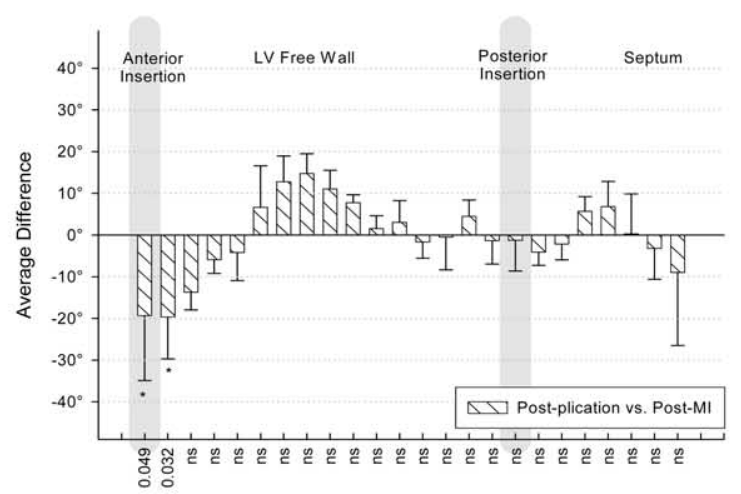

Basal

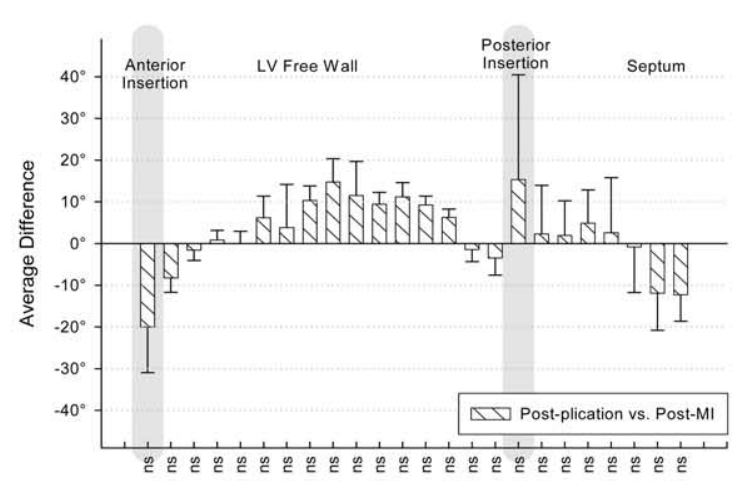

Figure 4. Differences in helix angles between groups are plotted around the circumference of the $L V$ in the $B Z(A)$, equatorial (B), and basal (C) regions: I, postinfarction versus normal; II, postplication versus infarction. Statistically significant $\boldsymbol{P}$ values $(\boldsymbol{P}<.05)$ are posted along the $\mathrm{x}$-axis. $n s$, Not significant. The operation significantly altered the helix angles in limited locations immediately adjacent to the repair (A-II). In general, the helix angle was not statistically different from normal after infarction or after the repair. 
A

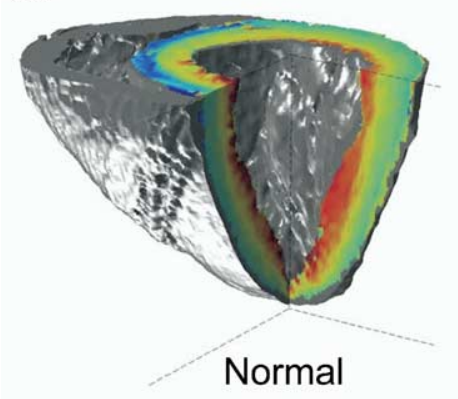

B

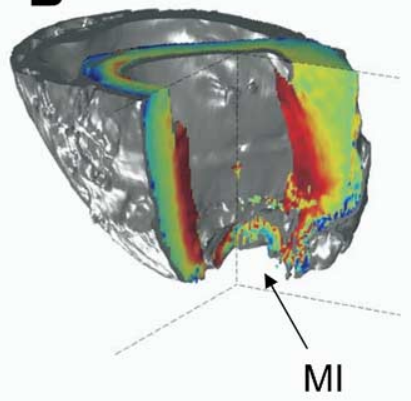

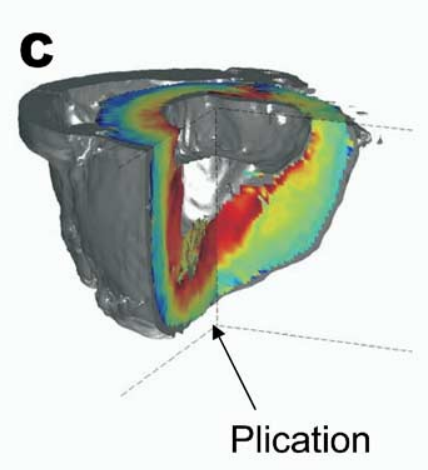

Figure 5. False-color helix angle maps showing helix angles in a cutaway view of the anterior (left) and lateral (right) walls in the normal (A), infarcted (B), and surgically repaired (C) LVs. All groups exhibit a similar trend of a negative helix angle at the epicardium to a positive helix angle at the endocardium. Color-scale units are in degrees.

infarct, this rotation of the helix angles is less pronounced in the equatorial region (anterior: $-19.6 \pm 10.1^{\circ}, P=.032$, Figure 3, B-I; lateral: $7.7 \pm 1.9^{\circ}, P=$ not significant, Figure $3, B-I I$ ), and almost disappears in the basal region (anterior: $-8.2 \pm 3.4^{\circ}, P=$ not significant, Figure 3, $C$-I; lateral: 11.5 $\pm 8.2^{\circ}, P=$ not significant, Figure $\left.3, C-I I\right)$. Along the $\mathrm{BZ}$ between these 2 sites, there was a smooth transition in the difference between the helix angles (Figure 4, A-II). In the equatorial and basal regions distal from the infarct, the same trend of the rotation of the helix angles was displayed after the operation (Figure 4, B-II and $C$-II). Going further around the ventricle, no significant differences were seen in the posterior or septal walls.

Figure 4 shows the difference between the groups, with underlying $P$ values listed if significant. Comparing aneurysmal with normal hearts, only one significant region appeared over all 72 regions; in general, there was no difference.

\section{Discussion}

In summary, the helical myofiber orientation did not change after MI. Of 72 locations compared after MI with normal hearts, only one region was statistically significant (Figure $4, A-I$ ), but even if there were no differences between the 2 groups, we would expect 3 or more regions to result in $P$ values of less than .05 by chance. Therefore we consider this to be a false-positive result. This finding of no change in the helix angles after MI confirms results from previous studies that showed no significant alteration of the helix angles in hypertrophic ${ }^{17,18}$ and infarcted hearts. ${ }^{10}$ Thus the hypothesis that dilated and diseased ventricles have abnormal helical myofiber architecture does not seem valid (Figure $4, I$ ). Because there is not an abnormal alteration of helix angles after infarction, ventricular restoration operations intent on restoring a normal, helical myofiber architecture might not be warranted.
In contrast, aneurysm plication did cause myofibers in the anterior BZ to rotate counterclockwise and those in the lateral BZ to rotate clockwise. Although not statistically significant in all regions, the pattern in the shift of the helix angles after the operation in the BZ repeated in the more distal equatorial and remote regions (Figure $4, B$ - II and $C-I I)$. Also, in this postplication versus post-MI comparison, 6 sites of statistical significance arose, and all were clustered around the location of the operation, where we would expect changes to be found if any existed (Figure 4, $A-I I$ and $B-I I)$. Therefore because the regions of statistical significance were clustered near the site of the operation and the pattern continued distal from the repair, we accept this finding as valid. This result shows that surgical intervention can alter the helix angles in regions adjacent to the repair, and thus this finding should be considered in the design of surgical restoration procedures.

\section{Implications for Regional Mechanics}

Mathematic models of the LV have demonstrated that a change in myofiber helix angles will have a profound effect on cardiac mechanics. ${ }^{5,23}$ Passive myocardium is known to be stiffest in the direction of the myofiber. ${ }^{4}$ In a cylindrical model of passive myocardium, the endocardial myofiber angle dominated diastolic mechanics; oblique fiber angles lead to greater ventricular twist. ${ }^{4}$ During active contraction, because of its larger moment arm, the epicardial myofiber angle dominates systolic contraction. ${ }^{6}$ In the present study myofibers in the anterior BZ in the infarcted hearts were circumferential at the epicardium and longitudinal at the endocardium (Figure 3, A-I ). Consequently, during diastole, we would expect less longitudinal stretch, more circumferential stretch, and limited twist in this region. The reverse deformation would be expected during systole. In the plicated hearts myofibers were oblique at the epicardium and 
endocardium and circumferential at the midwall at this location. During diastole, then, we would expect more longitudinal stretch, less circumferential stretch, and greater twist in this region relative to the infarcted hearts. Because this helix angle pattern reversed at the lateral BZ, we would expect the opposite effect in this region. MRI tagging studies $^{24}$ and finite element analysis ${ }^{25}$ should be able to confirm or reject this hypothesis.

As far as global LV performance, the effect of this rotation of the helix angles in the BZ after surgical intervention is too complex to predict; this is because the myofiber orientation varied regionally, and the geometry in these hearts was drastically changed by the intervention. Incorporating this helix angle data into a complex finite element analysis should allow wall stress and LV performance, as defined by the Starling relationship, to be computed. ${ }^{25}$

\section{Other Possible Mechanisms}

Similar to what we observed at the anterior and lateral BZs, Weis and associates ${ }^{26}$ reported a global rotation of helix angles in collagen-defective mice. They reported a $23^{\circ}$ clockwise rotation of the myofibers from collagen-defective to wild-type mice. Although the animal models were different (normal adult sheep and collagen-deficient mice), the similar results suggest that rotation of myofibers might partially be related to collagen remodeling in the myocardium after aneurysm plication. Enzymes such as matrix metalloproteinases and their enzymatic counterpart, tissue inhibitors of metalloproteinases, that regulate the collagenous extracellular matrix are known to be altered after an infarction. ${ }^{27}$ Therefore it is of interest whether these enzymes are involved in alterations to the extracellular matrix, which allow the myocytes to reorient along stress or strain gradients. Finite element analysis should allow the calculation of mechanical gradients.

\section{Limitations}

Although the surgical ventricular restoration procedure used in this study was aneurysm plication, variations of this procedure, such as the Dor and SAVER ${ }^{16}$ operations, have been developed to restore a more normal ventricular geometry. However, we hypothesized that if there was any change in fiber angle after surgical ventricular restoration, it would be seen most dramatically after aneurysm plication. In future studies (currently being pursued in our laboratory) on the Dor and SAVER procedures, it will be interesting to see whether the localized fiber angle changes near the anterior and lateral BZs reported here will also be present after these less severe shape changes.

The ovine LV aneurysm model is not a good model of the diffuse global disease generally leading to congestive heart failure. To our knowledge, though, there is no good animal model of this diffuse global disease. Gorman and colleagues $^{28}$ and Moainie and associates ${ }^{29}$ have recently developed 2 other infarct models in sheep. Of additional interest, then, would be comparing the results of the present study in ovine hearts with anterobasal ${ }^{29}$ or posterior infarcts. ${ }^{28}$ Also of interest would be allowing the ventricle to dilate for a longer time before surgical intervention. However, previous studies with this animal model have shown the LV to dilate to approximately 3 times normal endsystolic volume by 10 weeks after infarction ${ }^{20}$; keeping experimental animals alive for even longer would be expensive.

Given the distortion that occurs as a result of remodeling, the technique for locating the $\mathrm{BZ}$ area in the normal sheep is questionable. For example, $5 \mathrm{~cm}$ from the base in a remodeled heart is not the same spot as in a normal heart. The analysis was repeated with BZ samples on the normal hearts shifted $10 \mathrm{~mm}$ toward the base and again $10 \mathrm{~mm}$ toward the apex to address this issue. The $20 \mathrm{~mm}$ covered by this resampling analysis spans the approximately 4.5-mm long-axis length change reported previously in this ovine mode ${ }^{20}$ and therefore most likely contains the same spot as the sham hearts. In all 3 cases the results remained the same (data not shown).

This represents the first study to apply MR-DTI to a large animal model of LV aneurysm and surgical restoration. Because of motion complications currently hindering highresolution in vivo MR-DTI, ${ }^{30}$ this study of necessity compared fiber angles in excised hearts; the relevance of dead, noncontracting muscle fibers to the 3-dimensional contraction of the heart is completely unknown. Despite this ex vivo limitation, fiber angles were compared with all 3 groups in the same state. Studies on inflated hearts (before fixation) that better reflect in vivo geometry might be worthwhile in the future.

\section{Differences from Previous Methods}

Similar to the method proposed by Scollan and coworkers, ${ }^{8}$ we used a localized coordinate system to calculate the helix angles. However, because of the irregular geometry in these diseased hearts, we needed to reconstruct the entire epicardium. The helix angle is defined relative to the epicardial tangent plane, and consequently, the formation of that plane will affect the results. The epicardial tangent plane used by Scollan and coworkers was transverse to the imaging plane. ${ }^{8,12}$ This choice of the tangent plane limited the accuracy of their angle calculations in ventricular regions in which the epicardium was not perpendicular to the imaging plane. By computing angles relative to a reconstructed epicardium, we were able to explore regions on these irregular LVs that would not be accurately explored with previous methods. 


\section{Conclusion}

The helix angle does not change significantly after MI, and thus the pursuit of myofiber helix angle restoration with LV surgical restoration does not appear to be warranted. However, LV surgical restoration changes the helical myofiber direction localized near the site of the operation. This finding should be considered in the design of LV surgical restoration procedures.

We thank Dr Charles McCulloch, Professor and Head, Division of Biostatistics, University of California San Francisco, for his insightful guidance on the statistical analysis used in this study. We also thank Jason Hong for preparation of Figure 1.

\section{References}

1. Streeter DD Jr, Spotnitz HM, Patel DP, Ross J Jr, Sonnenblick EH. Fiber orientation in the canine left ventricle during diastole and systole. Circ Res. 1969;24:339-47.

2. Vetter FJ, McCulloch AD. Three-dimensional analysis of regional cardiac function: a model of rabbit ventricular anatomy. Prog Biophys Mol Biol. 1998;69:157-83.

3. Greenbaum RA, Ho SY, Gibson DG, Becker AE, Anderson RH. Left ventricular fibre architecture in man. Br Heart J. 1981;45:248-63.

4. Guccione JM, McCulloch AD, Waldman LK. Passive material properties of intact ventricular myocardium determined from a cylindrical model. J Biomech Eng. 1991;113:42-55.

5. Vendelin M, Bovendeerd PH, Engelbrecht J, Arts T. Optimizing ventricular fibers: uniform strain or stress, but not ATP consumption, leads to high efficiency. Am J Physiol Heart Circ Physiol. 2002;283: H1072-81.

6. Ingels NB Jr. Myocardial fiber architecture and left ventricular function. Technol Health Care. 1997;5:45-52.

7. Hsu EW, Muzikant AL, Matulevicius SA, Penland RC, Henriquez CS. Magnetic resonance myocardial fiber-orientation mapping with direct histological correlation. Am J Physiol Heart Circ Physiol. 1998;274: H1627-34.

8. Scollan DF, Holmes A, Winslow R, Forder J. Histological validation of myocardial microstructure obtained from diffusion tensor magnetic resonance imaging. Am J Physiol Heart Circ Physiol. 1998;275: H2308-18.

9. Holmes AA, Scollan DF, Winslow RL. Direct histological validation of diffusion tensor MRI in formaldehyde-fixed myocardium. Magn Reson Med. 2000;44:157-61.

10. Chen J, Song SK, Liu W, McLean M, Allen SJ, Tan J, et al. Remodeling of cardiac fiber structure after infarction in rat quantified with diffusion tensor MRI. Am J Physiol Heart Circ Physiol. 2003;285: H946-542003

11. Geerts L, Bovendeerd P, Nicolay K, Arts T. Characterization of the normal cardiac myofiber field in goat measured with MR-diffusion tensor imaging. Am J Physiol Heart Circ Physiol. 2002;283:H139-45.

12. Scollan DF, Holmes A, Zhang J, Winslow RL. Reconstruction of cardiac ventricular geometry and fiber orientation using magnetic resonance imaging. Ann Biomed Eng. 2000;28:934-44.
13. Buckberg GD. Congestive heart failure: treat the disease, not the symptom-return to normalcy. J Thorac Cardiovasc Surg. 2001;121: 628-37.

14. Buckberg GD. Basic science review: the helix and the heart. $J$ Thorac Cardiovasc Surg. 2002;124:863-83.

15. Buckberg GD, Coghlan HC, Torrent-Guasp F. The structure and function of the helical heart and its buttress wrapping. VI. Geometric concepts of heart failure and use for structural correction. Semin Thorac Cardiovasc Surg. 2001;13:386-401.

16. Athanasuleas CL, Stanley AW Jr, Buckberg GD, Dor V, DiDonato M, Blackstone EH. Surgical anterior ventricular endocardial restoration (SAVER) in the dilated remodeled ventricle after anterior myocardial infarction. RESTORE group. Reconstructive Endoventricular Surgery, returning Torsion Original Radius Elliptical Shape to the LV. J Am Coll Cardiol. 2001;37:1199-209.

17. Carew TE, Covell JW. Fiber orientation in hypertrophied canine left ventricle. Am J Physiol Heart Circ Physiol. 1979;236:H487-93.

18. Pearlman ES, Weber KT, Janicki JS, Pietra GG, Fishman AP. Muscle fiber orientation and connective tissue content in the hypertrophied human heart. Lab Invest. 1982;46:158-64.

19. Markovitz LJ, Savage EB, Ratcliffe MB, Bavaria JE, Kreiner G, Iozzo $\mathrm{RV}$, et al. Large animal model of left ventricular aneurysm. Ann Thorac Surg. 1989;48:838-45.

20. Ratcliffe MB, Wallace AW, Salahieh A, Hong J, Ruch S, Hall TS. Ventricular volume, chamber stiffness, and function after anteroapical aneurysm plication in the sheep. J Thorac Cardiovasc Surg. 2000;119: 115-24.

21. Papadakis NG, Xing D, Huang CL, Hall LD, Carpenter TA. A comparative study of acquisition schemes for diffusion tensor imaging using MRI. J Magn Reson. 1999;137:67-82.

22. Hsu EW, Henriquez CS. Myocardial fiber orientation mapping using reduced encoding diffusion tensor imaging. J Cardiovasc Magn Reson. 2001;3:339-47.

23. Bovendeerd PH, Arts T, Huyghe JM, van Campen DH, Reneman RS. Dependence of local left ventricular wall mechanics on myocardial fiber orientation: a model study. J Biomech. 1992;25:1129-40.

24. Ozturk C, McVeigh ER. Four-dimensional B-spline based motion analysis of tagged MR images: introduction and in vivo validation. Phys Med Biol. 2000;45:1683-702.

25. Guccione JM, Moonly SM, Wallace AW, Ratcliffe MB. Residual stress produced by ventricular volume reduction surgery has little effect on ventricular function and mechanics: a finite element model study. J Thorac Cardiovasc Surg. 2001;122:592-9.

26. Weis SM, Emery JL, Becker KD, McBride DJ Jr, Omens JH, McCulloch AD. Myocardial mechanics and collagen structure in the osteogenesis imperfecta murine (oim). Circ Res. 2000;87:663-9.

27. Wilson EM, Moainie SL, Baskin JM, Lowry AS, Deschamps AM, Mukherjee R, et al. Region- and type-specific induction of matrix metalloproteinases in post-myocardial infarction remodeling. Circulation. 2003;107:2857-63.

28. Gorman JH 3rd, Gorman RC, Plappert T, Jackson BM, Hiramatsu Y, St John-Sutton MG, et al. Infarct size and location determine development of mitral regurgitation in the sheep model. $J$ Thorac Cardiovasc Surg. 1998;115:615-22.

29. Moainie SL, Gorman JH 3rd, Guy TS, Bowen FW 3rd, Jackson BM, Plappert T, et al. An ovine model of postinfarction dilated cardiomyopathy. Ann Thorac Surg. 2002;74:753-60.

30. Dou J, Reese TG, Tseng WY, Wedeen VJ. Cardiac diffusion MRI without motion effects. Magn Reson Med. 2002;48:105-14. 